\title{
Advanced technique for the treatment of chronic calculous pancreatitis using endoscopic ultrasound-guided pancreatic duct drainage
}

A 64-year-old man who underwent distal gastrectomy with Billroth II reconstruction for duodenal ulcer perforation was hospitalized for painful chronic pancreatitis. The recurrent pain was caused by calculous obstruction of the pancreatic duct, resulting in upstream ductal hypertension. Computed tomography showed stones and a dilated main pancreatic $\operatorname{duct}(\mathrm{MPD})$ ( $>$ Fig. 1 )

We performed endoscopic retrograde pancreatography (ERP); however, we could not insert the guidewire deeply ( Fig.2). Therefore, we tried endoscopic ultrasound-guided pancreatic duct drainage (EUS-PD). However, the guidewire could not be advanced across the papilla and tended to coil within the MPD. Hence, a fully covered metal stent was placed from the MPD to the stomach (> Fig.3).

After the fistula had matured, we again attempted guidewire advancement, which was difficult. Therefore, an intraductal pancreatoscope (IDP; SpyGlass DS system; Boston Scientific Corp., Natick, Massachusetts, USA) was inserted through the pancreatogastrostomy to facilitate direct visualization. The IDP image indicated complete obstruction of the MPD by the stones. Therefore, electrohydraulic lithotripsy (EHL; Lithotron

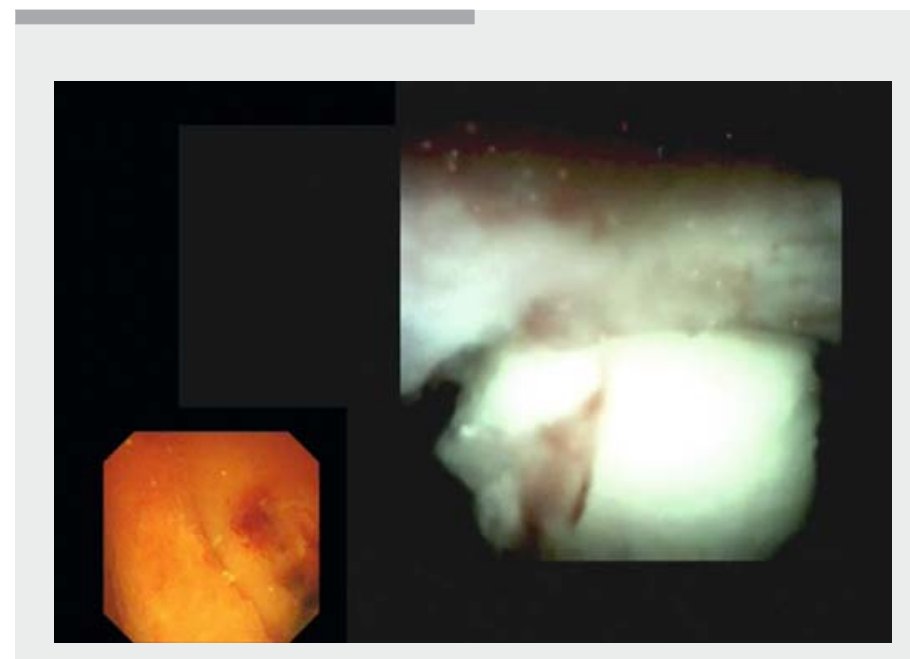

Video 1 The metal stent was easily removed. The intraductal pancreatoscope was inserted through the pancreatogastrostomy. The images show complete obstruction of the main pancreatic duct by pancreatic stones. Electrohydraulic lithotripsy was performed to fragment the stones. Finally, the guidewire could be negotiated through the minor papilla.

EL 27 Compact; Walz Elektronik, Rohrdorf, Germany) was performed. The stones could be fragmented, allowing the guidewire to be negotiated through the minor papilla ( $\triangleright$ Fig. 4 ; $\triangleright$ Video 1 ). We exchanged the scope for a colonoscope, dilated the minor papilla using a balloon up to $4 \mathrm{~mm}$, and finally placed a $7 \mathrm{Fr}$ single-pigtail stent from the minor papilla to the fistula using a rendezvous technique ( $\mathbf{F i g . 5}$ ). There were no adverse events.

Although ERP is the conventional method for treating pancreatic ductal obstruction, it is sometimes challenging in patients with tight stenosis, complete ductal obstruction, or surgically altered anatomy [1]. Recently, EUS-PD has been
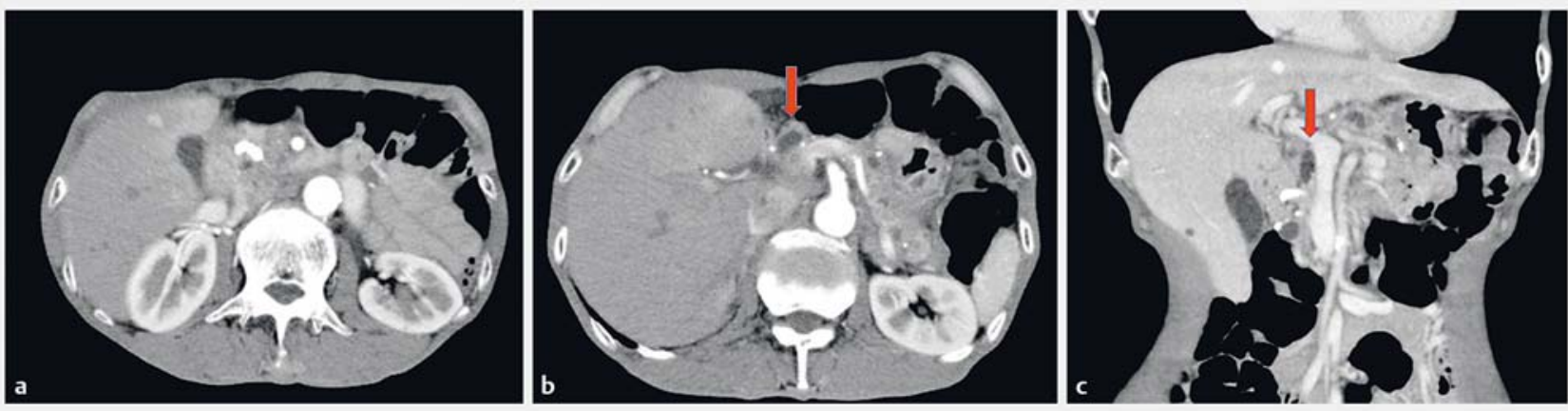

- Fig. 1 Computed tomography images. a Pancreatic stones in the main pancreatic duct. b Dilation of the upstream pancreatic duct (red arrow). c Coronal image showing the stones and the dilated main pancreatic duct (red arrow). 

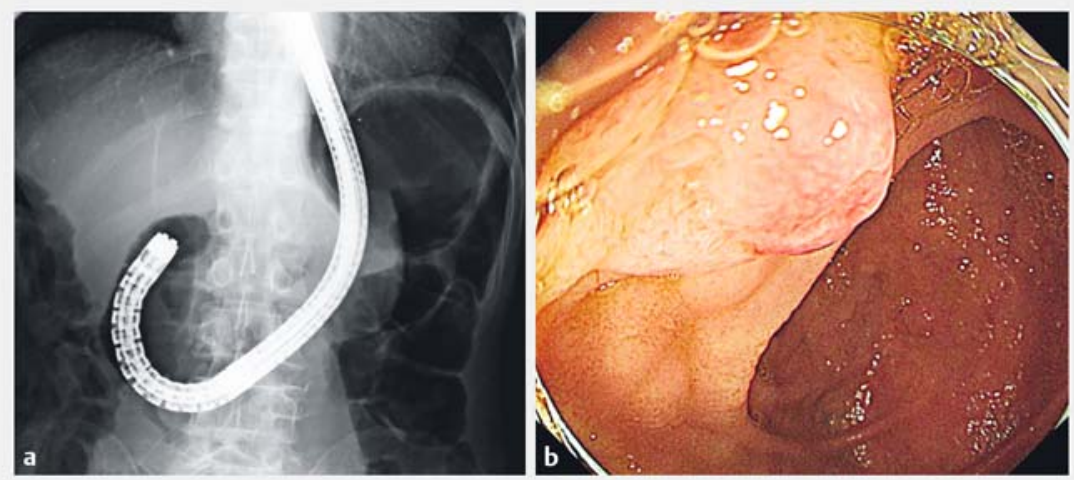

reported to be useful in such cases [25]. We report a first case: after formation of the EUS-PD fistula, EHL was easily performed using an IDP inserted via the pancreatogastrostomy. Our approach and treatment method could become one of the choices for such patients.

Endoscopy_UCTN_Code_TTT_1AR_2AI

Fig. 2 Endoscopic retrograde pancreatography. a Radiography showed that the scope reached the major papilla with the aid of a colonoscope. $\mathbf{b}$ Endoscopic view of the major papilla; we could not adjust the angle because of surgically altered anatomy, and hence, we could not insert the guidewire deeply.
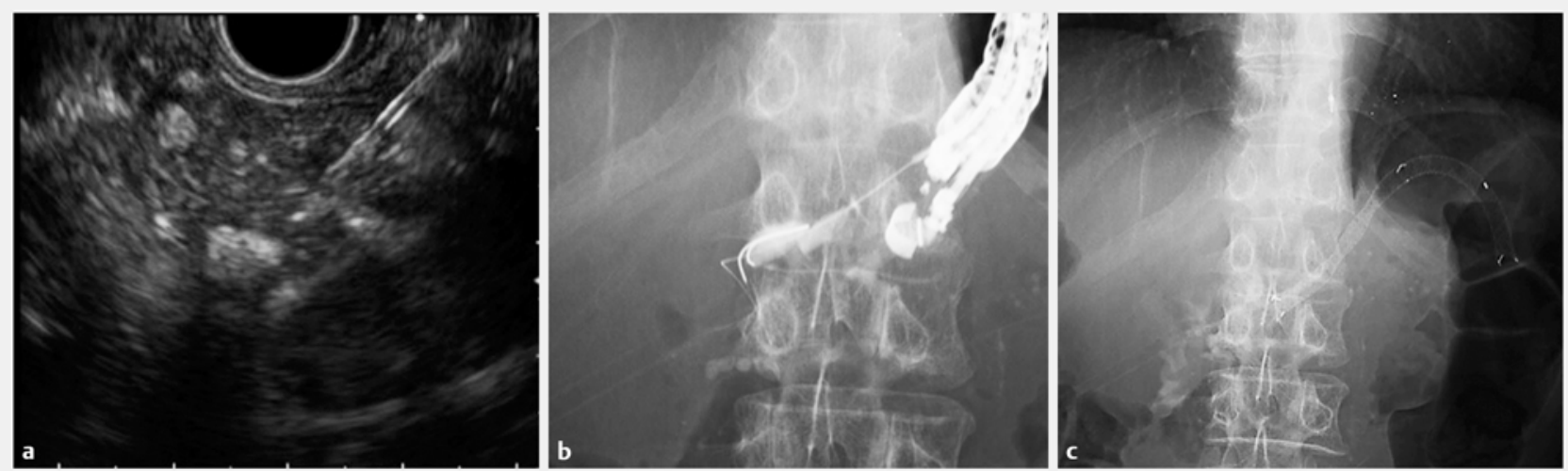

- Fig. 3 Endoscopic ultrasound-guided pancreatic duct drainage. a A 19-gauge needle was used to puncture the main pancreatic duct. b Radiography showed that the guidewire could not be advanced across the papilla, and instead, tended to coil within the main pancreatic duct. c A fully covered metal stent was placed across the pancreatogastrostomy.
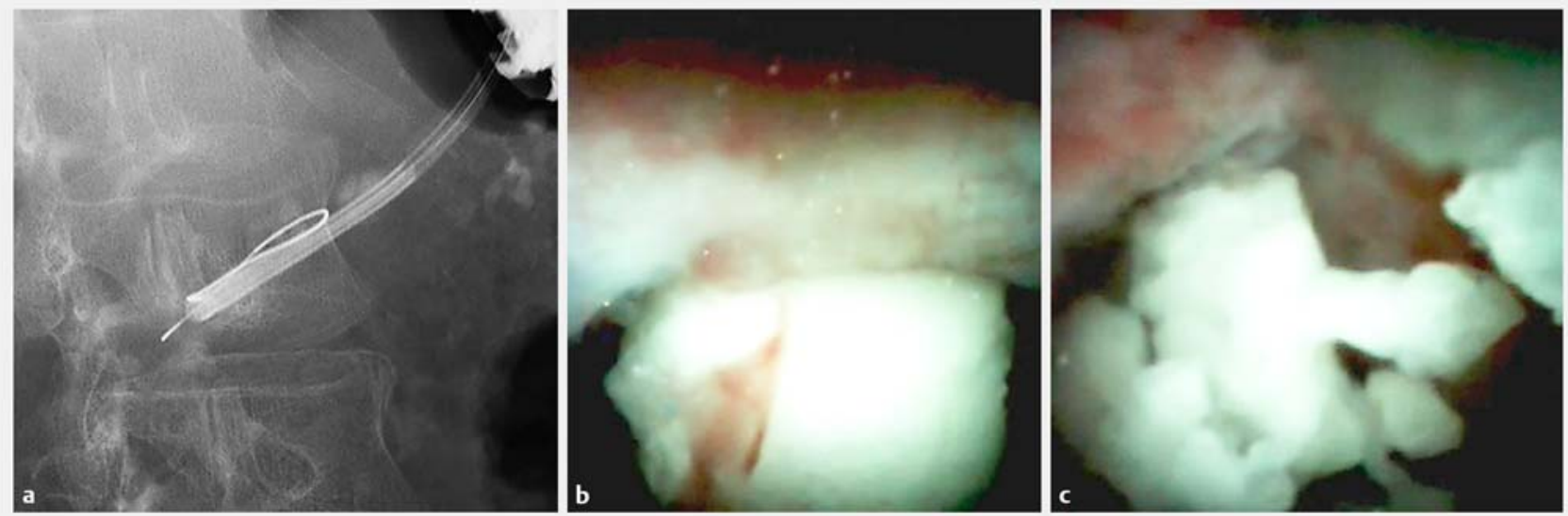

- Fig. 4 Intraductal pancreatography and electrohydraulic lithotripsy. a Radiographic image showing insertion of the intraductal pancreatoscope through the pancreatogastrostomy to facilitate direct visualization. $\mathbf{b}$ The intraductal pancreatoscope revealed complete obstruction of the main pancreatic duct by pancreatic stones. c The stones were fragmented using electrohydraulic lithotripsy. 

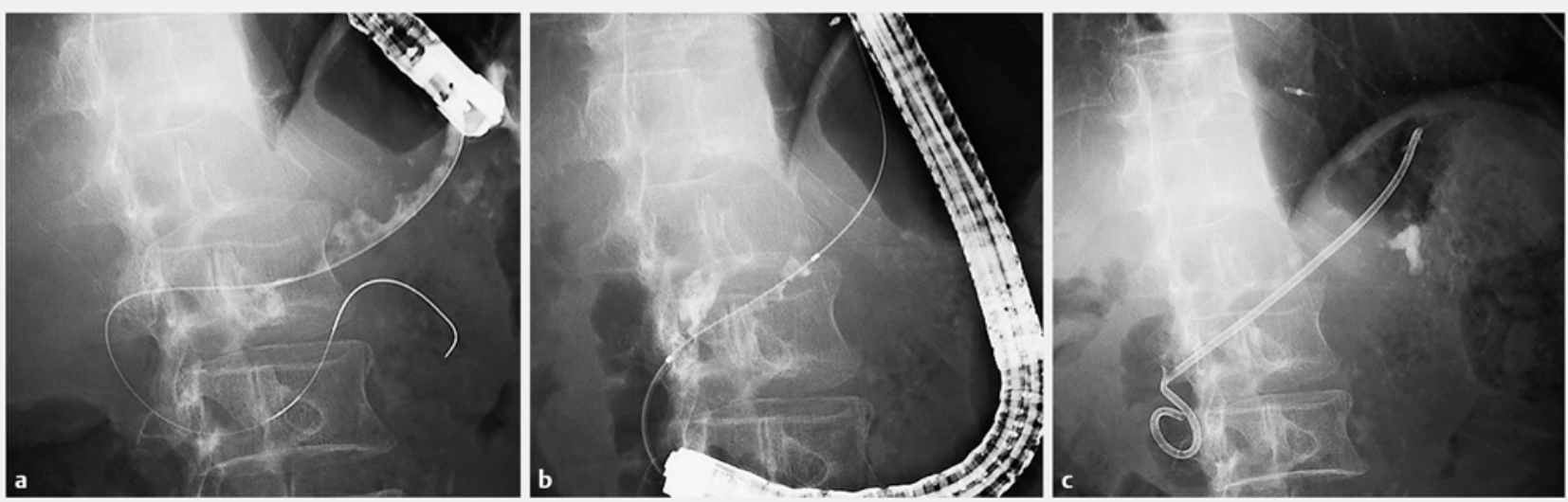

- Fig.5 Rendezvous technique as seen on radiographic images. a After the pancreatic stone was fragmented using electrohydraulic lithotripsy, the guidewire could be negotiated through the minor papilla. b The scope was exchanged for a colonoscope. c A single-pigtail stent was inserted from the minor papilla to the fistula.

\section{Competing interests}

None

The Authors

Nozomi Okuno', Kazuo Hara', Nobumasa Mizuno', Susumu Hijioka', Takamichi Kuwahara', Akashi Fujita', Yasumasa Niwa',2

1 Department of Gastroenterology, Aichi Cancer Center Hospital, Nagoya, Japan

2 Department of Endoscopy, Aichi Cancer Center Hospital, Nagoya, Japan

\section{Corresponding author}

\section{Kazuo Hara, MD}

Department of Gastroenterology, Aichi Cancer Center Hospital, Kanokoden, Chikusa-ku, Nagoya, Aichi 464-8681, Japan Fax: +81-52-7635233

khara@aichi-cc.jp

\section{References}

[1] Widmer J, Sharaiha RZ, Kahaleh M. Endoscopic ultrasonography-guided drainage of the pancreatic duct. Gastrointest Endosc Clin N Am 2013; 23: 847-861

[2] Chen YI, Levy M], Moreels TG et al. An international multicenter study comparing EUSguided pancreatic duct drainage with enteroscopy-assisted endoscopic retrograde pancreatography after Whipple surgery. Gastrointest Endosc 2017; 85: 170-177

[3] Oh D, Park do H, Cho MK et al. Feasibility and safety of a fully covered self-expandable metal stent with antimigration properties for EUS-guided pancreatic duct drainage: early and midterm outcomes (with video). Gastrointest Endosc 2016; 83: 366 - 373

[4] Tyberg A, Sharaiha RZ, Kedia P et al. EUSguided pancreatic drainage for pancreatic strictures after failed ERCP: a multicenter international collaborative study. Gastrointest Endosc 2017; 85: $164-169$

[5] Ergun M, Aouattah T, Gillain C et al. Endoscopic ultrasound-guided transluminal drainage of pancreatic duct obstruction: long-term outcome. Endoscopy 2011; 43: $518-525$

\section{Bibliography}

DOI https://doi.org/10.1055/s-0043-110666

Published online: 14.6.2017

Endoscopy 2017; 49: E197-E199

(c) Georg Thieme Verlag KG

Stuttgart · New York

ISSN 0013-726X

\section{ENDOSCOPY E-VIDEOS}

https:/|eref.thieme.de/e-videos

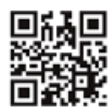

Endoscopy E-Videos is a free access online section, reporting on interesting cases and new techniques in gastroenterological endoscopy. All papers include a high quality video and all contributions are freely accessible online.

This section has its own submission website at https://mc.manuscriptcentral.com/e-videos 